\title{
Application of the Original Movies in English and American Literature Teaching
}

\author{
Qianming Zhao
}

Weinan Normal University, Weinan, 714000, China

\author{
Keywords: British and American Literature; Classroom Teaching; Original Film
}

\begin{abstract}
Anglo-American literature is an important part of world literature. It systematically reflects the development of the history, culture, religion, arts and natural sciences in Anglo-American countries. Therefore, it is of crucial importance to improve the effectiveness of Anglo-American literary teaching. The new curriculum reform calls for the reform of the old-fashioned and boring teaching methods of traditional Anglo-American literature to enhance the image, vividness and diversity of teaching. Therefore, the application of the original film in English and American literature class can strengthen students' cognition of literary works and deepen the comprehension of the works. Fully stimulate their interest in learning. The article mainly discusses the application of the original film in Anglo-American literature teaching.
\end{abstract}

\section{The Application Advantages of the Original Movie in Anglo-American Literature}

After more than a hundred years' development, the film has been developing in a high-tech and diversified direction. Among them, the works adapted from the original works of classic literature are so numerous that the advantages of the original film as an adjunct to Anglo-American literature are beyond doubt:

Students only show a strong interest in learning objects and enthusiasm can really stimulate their motivation to learn, get a better learning effect. Traditional Anglo-American literature is mostly taught by teachers. Students listen, the forms are dull, the contents are boring and cannot stimulate students' enthusiasm for learning. The original film is a collection of sound, light, video and other elements. Students cannot only enjoy the more interesting videos, but also master the knowledge in the process of watching the videos. By combining the contents of the videos with the textbooks, students are greatly encouraged to learn interest and urge students to read English and American literature related to movies and enhances the learning effect.

Language acquisition requires a good language environment. Non-native English speakers lack the necessary language environment. However, the original film contains a great deal of dialogue or soliloquy, which becomes the best material to improve students' language ability. After a period of study, college students already have the ability to read, write and translate. By watching videos, they can review the application of what they have learned and improve their speaking ability and listening skills. Compared with the textbooks, the original film not only has vivid images, twists and turns of the story, more original language material, students master the knowledge in the process of watching the movie, improve the effectiveness of language learning.

Literature comes from life. Many Anglo-American literary works have specific historical background and events. The more they understand these cultural backgrounds, the more favorable their students acquire knowledge and eliminate reading disabilities. The original film precisely creates a true culture for students Atmosphere, the students watch the screen you can experience the movie described by the background and emotional expression. Such as the Red Hat of Sherlock in The Merchant of Venice and the era background of the "Gone with the Wind" in the Civil War, etc. Visual expression can further deepen students' understanding of Anglo-American culture and explore its connotation. In addition, the original movie will also show the different styles of architectural styles, styles, costume styles, these are through the reading of Anglo-American works cannot be intuitive access. 


\section{The Application Principle of the Original Movie in Anglo-American Literature Teaching}

The original film in Anglo-American literature teaching should follow the following principles:

The so-called correctness is the correct understanding of teaching objectives. The original film is only one of the means of Anglo-American literature teaching, its ultimate goal is to serve the teaching activities, so the choice and playback must focus on teaching objectives. The so-called open as long as it can improve the humanistic quality of students, help students understand the original works can be used as teaching material, to guide students from a diversified perspective of literary works, and even a film may not have to explain a particular work Relationship, but a scene or theme in the film useful for students to understand literary works, but also choose to watch. Finally, put a reasonable play principle. Teachers need to carefully consider how to play the video in the classroom, to ensure that the film material application is reasonable and appropriate, cannot watch the movie into a relaxed entertainment. In the actual classroom, the teacher should clearly convey the purpose of the screenings to the students, and should not make them deviate from the teaching objectives. According to the teaching objectives, students should design related questions, watch the students and think after reading them, and record the thinking results for discussion in the classroom. In addition, the teacher can also make appropriate comments and discussions on the contents of the movie during the student watching process, encourage students to develop critical thinking and transfer students' interest in the movie to reading.

\section{The Application Strategy of the Original Movie in the Anglo-American Literature Teaching}

Anglo-American literary teaching in the application of the original movie can start from the following aspects:

Teachers should do a good job preparatory work before class, according to the text of the literature to read the text to choose loyal to the original movie, and before watching the impact of the teacher to guide students to read the text, focus on the text, the first reading of the British and American literary works, analysis lay a solid foundation for students to improve their humanities. Although the original film respects the spirit of the original filming, its expression with the text is two different forms of artistic expression. The theme, character, plot, background, time and space are all set according to the original arrangement. The teacher must let the students read The original can avoid preconceived problems caused by watching movies first. For example, "Forrest Gump", which contains a series of historical events such as the Civil War, Elvis Presley, Lincoln assassination, Watergate and other issues, teachers must let students understand these background of the times, give students full time to think before they can watch movies at the same time completely cross-cultural communication. In addition, the beauty of the language of the original text is also the film art cannot be fully expressed, such as the "Venice businessman" script, the Jewish Sherlock resolutely asked Antonio chest a pound of meat, the fragment refined language, poetic, making Sherlock The shape of the image is very rich, this language writing style is the film art cannot be expressed. Therefore, teachers should guide students to taste the beauty of classic literature and really grasp the essence of the film. In the actual teaching, teachers should explain and analyze the characterization, plot description, narrative method, author style and so on through the words and sentences to make the students have accurate grasp and profound understanding of the meaning of the text, and then read the basic text On the screening of the movie, so that students will read the text combined with the movie fragment, analysis of similarities and differences, focusing on the text.

Film usually works on the style of literary works in many ways, including translation style adaptation, frame style adaptation and free style adaptation, among which the translation adaptation is the most faithful to the original works. Only by respecting the original works can the students understand literature accurately works. Such as "Romeo and Juliet" is the standard translation adaptation, try not to reveal the traces of adaptation, these films can best reflect the spirit of the original, whether it is language, storyline or theme are the interpretation of the original works, so students can Watch movies repeatedly to deepen understanding of the original. Frame change is the 
director, the actor's understanding of the original and sentiments into the movie, such as "Twenty-two military regulations" is a frame-based adaptation, this type of movie can take part of the scene, the fragment for classroom teaching. Freestyle changes are completely deviated from the original storyline, such as director Mike Almer Reid directed the film "Hamlet" is a reconstructed film. English and American literature teaching class should be based on the choice of translation of the original movie, if you have to choose the latter two types of movies, the teacher should do a good job guiding the movie appreciation into the other points, such as "Hamlet" You can downplay its theme, ignore the postmodern factors in the film, and focus your appreciation on the analysis of human nature.

A class of 45 minutes cannot play a full 90-120 minutes of the movie, but with two or three lessons time to play a movie is even more impractical, so the teacher should control the play of the original movie in the classroom rhythm, select the appropriate clips, according to the pace of classroom teaching reasonable control parking. Before the screening of the film, the students have formed a certain understanding of the original. Teachers only need to make a brief introduction to the film so as to guide the students to focus their attention on the film as much as possible, but they do not have to spend too much time on the introduction of the film, lest the Anglo-American Literary classroom into a movie review class. In addition, for some of the more original movies, the teacher after the assessment that the students need to watch the whole film, you can take out 3-4 hours outside the class after class hours, organize students to watch and discuss, not to waste the normal class hours, but also give full play to the role of film as a special method for studying Anglo-American literature. In addition, the teacher can also reasonably collect the static pictures related to the film, and apply the multimedia technology to show students vivid and vivid image resources to help students understand the film and improve the classroom effect. In the analysis of British and American literary works, especially in drama and fiction, teachers can use multimedia super king to capture pictures, freeze pictures of certain characters, and deepen students' learning. For example, "Wuthering Heights" is Emily Bronte's novel, the syllabus stipulates that it is non-key teaching content, this time you can choose the film in the movie information production courseware, first collected from the film material, through the design and layout After the application of slide coverage, hidden, cascading techniques such as insert pictures, coupled with the refined text to introduce the "wuthering Heights," the relevant knowledge of an intuitive and fast presentation in front of the students.

\section{Conclusion}

In short, the English version of the original film language dialogue from the real social background, with strong reality, and according to the literary masterpiece adaptation of the movie is not lack of cultural heritage, it is very suitable for the study of language majors, but also for Anglo-American Literature Teaching provides a new perspective and effective way. However, films and literary works are two different forms of art. Literary works use language and characters as medium of communication. Their relationship with artistic images is indirect, and films are mediated by visual images. The difference between the two determines the application of the original film teaching in Anglo-American literature class can only be an aid. Therefore, in the process of teaching, teachers should constantly emphasize the basic position of texts in Anglo-American literature teaching and realize the organic combination of "text culture" and "image culture" with the help of the visual representation form of film, take its essence and go to its dross, to achieve the advantages of different teaching methods complement each other and effectively improve students' learning effectiveness and cultural accomplishment.

\section{References}

[1] Wang Jingjing, Chi Lixia. Analysis of the adaptation of famous movies in the English and American literature teaching aids [J]. Science and Technology Information, 2015 (21): 38-40 
Sun Yanna. "Yang" and "Abandonment" of Classic Literature Film under the Impact of Visual Culture in English and American Literature Curriculum [J]. Educational and Instruction Research, 2015 (5): 154-155

[3] Yi Ruiying. On the digital teaching platform on English and American literature teaching auxiliary role [J]. Zhenjiang College of Art, 2015 (6): 209-211

[4] Liu Min. English movie in college English Anglo American literature elective teaching in the auxiliary role [J]. Overseas English, 2015 (4): 78-79

[5] Liu Pingping. English original film and Anglo-American literature teaching [J]. Film Review, 2016 (5): 38-40

Long Qianhong. Film and English Listening and Speaking Teaching [J]. Foreign language teaching, 2013 (6): 98-100

[7] Anglo-American literary cloud. The influence of constructivist learning theory on foreign language classroom teaching [J]. Journal of Sichuan University of Foreign Languages, 2016 (5): 246-247

[8] Wang Songlin, Li Hongqin. The literary, cultural and film teaching in Anglo-American literature [J]. Foreign Language and Foreign Languages Teaching, 2016 (9): 37-38 